\title{
A DIMENSÃO SERVIÇO NO TRABALHAR: UMA ANÁLISE CRÍTICA
}

\author{
Ana Cláudia Barbosa da Silva Roosli (Psicologia - UEL) \\ Sonia Regina Vargas Mansano (Psicologia - UEL)
}

\section{RESUMO}

A prestação de serviços tornou-se um campo de trabalho em ascensão no nosso país. Esse crescimento coloca para os pesquisadores da área de Psicologia do Trabalho o desafio de compreender as transformações sociais mais recentemente geradas pela dimensão serviço no trabalhar. Zarifian (2007) vincula a produção do serviço ao reposicionamento das competências profissionais, que ganham relevância à medida que a realidade laboral é reconfigurada e os limites dos velhos modelos deixam entrever sua obsolescência. Baseado nisso, o presente estudo tem por objetivo compreender a produção do serviço recorrendo a uma abordagem crítica. Assim, o estudo foi dividido em três momentos: a definição de serviço e sua articulação às competências profissionais, as novas exigências subjetivas colocadas para o trabalhador e, por fim, as implicações éticas e políticas dessa atividade para a saúde do profissional. Como conclusão parcial, pode-se dizer que a prestação de serviços mobiliza o trabalhador em dimensões de ordem afetiva e subjetiva. Concomitantemente, porém, ela exige de seus destinatários uma contrapartida de atuação que nem sempre é evidenciada e conhecida. Tal negligência pode colocar em xeque a qualidade do serviço prestado, trazendo prejuízos à saúde e bem estar de quem o executa.

Palavras-chave: produção de serviço, saúde do trabalhador, psicologia social

\section{INTRODUÇÃO}

A prestação de serviço esteve, nos últimos anos, em ascensão nos campos de trabalho em nosso país. Esse crescimento coloca para os pesquisadores e profissionais que atuam na subárea da Psicologia do Trabalho e Organizacional o desafio de compreender as transformações recentes, bem como analisar os efeitos que elas trazem para o cotidiano daqueles que disponibilizam seu tempo, sua energia e, principalmente, sua vitalidade subjetiva a esse tipo de atividade.

Nesta direção, para análise das transformações no processo de trabalho, adotamos como marco teórico a noção de serviço. Ao propor o uso do conceito de serviço, Zarifian (2001b) objetiva demonstrar como ele é capaz de exprimir uma nova maneira de ver e avaliar a produção em qualquer setor. Portanto, em seu entender, este conceito é capaz de representar a produção da agricultura, da indústria ou a prestação de serviços, importando "[...] compreender uma mudança que os atinge, a ambos, apesar de incontestáveis diferenças entre eles" (p. 97).

Produzir um serviço envolve uma gama de habilidades que vão desde aquelas mais técnicas, passíveis de treinamento e qualificação, até as afetivas e subjetivas que dizem respeito às relações sociais e à história de vida do trabalhador. Hubault destaca que '(...) existe a relação de serviço desde que a 'solução técnica' se demonstra 


\section{SEMINÁRIO DE PESQUISA EM CIÊNCIAS HUMANAS - SEPECH \\ Humanidades, Estado e desafios didático-científicos \\ Londrina, 27 a 29 de julho de 2016}

insuficiente para a realização dos objetivos de uma prestação direcionada a outra pessoa" (2011, p. 125).

A partir de resultados parciais produzidos pelo projeto de pesquisa "O trabalho na Estratégia de Saúde da Família (SF): uma análise do ponto de vista da atividade", constata-se que a consolidação do serviço exige tanto recursos organizacionais quanto pessoais dos trabalhadores. Em busca de melhor compreensão da complexidade em curso na produção do serviço, considera-se necessário incorporar à análise uma perspectiva crítica. Neste caso, recorreu-se à produção elaborada pelo projeto de pesquisa "Sustentabilidade afetiva: viver, amar e trabalhar nas cidades".

Assim, o que buscaremos neste estudo é identificar as múltiplas exigências colocadas aos trabalhadores, acrescentando ao debate uma abordagem crítica em relação aos modos de vida que estamos ajudando a construir, seja na condição de profissionais ligados à área do trabalho, seja como trabalhadores que também prestam serviços.

Para tanto, o estudo foi dividido em três momentos: primeiramente, será definida a noção de serviço. Em seguida, será analisada sua articulação com as competências profissionais em evidência na contemporaneidade, bem como as novas exigências subjetivas colocadas para o trabalhador. Por fim, as implicações éticas e políticas da produção de serviço serão problematizadas no que se refere às possibilidades de saúde do trabalhador.

\section{DEFININDO A NOÇÃO DE SERVIÇO}

Zarifian (2003) vincula a emergência da "relação de serviço" à expansão e legitimação sociais do modelo da competência. Do ponto de vista da relação com o trabalho, o desafio da competência pode ser compreendido como uma volta do trabalho para o trabalhador. Rejeitando-se uma visão puramente linear do desenvolvimento histórico das sociedades, Zarifian (2003) afirma que o desafio atual da competência está diretamente ligado às ações administrativas realizadas no início da industrialização e aos debates práticos do século XVIII. Ele relembra o cenário político da época em que a vertente industrial do capitalismo praticamente impôs a separação do camponês ou do artesão de sua própria atividade, vinculando-os, desde então, a um tipo de trabalho objetivado, com tarefas prescritas, segmentadas e repetitivas que passaram a ser atribuídas ao indivíduo.

Esta separação produziu os mais diversos efeitos, dentre os quais se destaca uma nova configuração para o trabalho, que passou a ser objetivado, prescrito, racionalizado e determinado de fora, independentemente daquele que o realizava. Assim, o trabalhador foi praticamente equiparado a um objeto, sendo concebido como portador apenas das capacidades básicas necessárias para realizar um tipo de atividade repetitiva e mecânica.

Sair dessa concepção que vincula o trabalhador a um conjunto de atividades prescritas e a um posto fixo de trabalho implica um rompimento decisivo para com essa racionalidade produtivista. Somente esse rompimento abriria espaço para a retomada do trabalho como expressão direta das competências construídas historicamente na relação com os outros e na produção de formas de vida diferenciadas e singulares em contexto laboral. 


\section{SEMINÁRIO DE PESQUISA EM CIÊNCIAS HUMANAS - SEPECH \\ Humanidades, Estado e desafios didático-científicos \\ Londrina, 27 a 29 de julho de 2016}

Cabe destacar, porém, que a defesa de uma concepção de trabalho na qual seus agentes tornam-se a expressão direta da potência do pensamento, das ações, do conhecimento e do engajamento social não pode levar a uma visão universalista da competência. Ela só se manifesta em relação a algo ou alguém que está localizado em uma circunstância específica e em um tempo histórico preciso. Nesse caso, não se trata de uma concepção predefinida e identitária de competência, mas de uma relação situada na qual a competência pode vir a ser inventada, mobilizada e transformada, fazendo uso tanto dos recursos da organização quanto das habilidades subjetivas dos sujeitos envolvidos na atividade.

Assim, Zarifian (2003) enfatiza que o modelo da competência só pode desenvolver-se plenamente apoiando-se na iniciativa dos próprios trabalhadores. Para o autor, esta é uma questão decisiva, que exige uma profunda transformação nas condições de produção bem como na organização das empresas e das atividades. Temse aqui um salto qualitativo: essa transformação está baseada na relação entre competência e produção de serviço. Portanto, a questão do serviço não tem como ponto de partida a tarefa de "agradar" a um cliente que passa, em especial no final do século XX, a ser tratado como "rei”. A posição sustentada por Zarifian é:

a questão do serviço emergiu progressivamente como uma modalidade de redefinição profunda das condições da produtividade e, portanto, como fonte decisiva (para o capitalismo em primeiro lugar, para os usuários em seguida) de uma retomada do crescimento dos ganhos de produtividade (ZARIFIAN, 2003, p. 97).

Zarifian (2001a) destaca, entretanto, que embora a noção de serviço seja fundamental para a organização do trabalho contemporânea e que cada vez mais conquiste espaços nas diferentes esferas produtivas, o tratamento a ela conferido ainda é orientado por uma visão concorrencial e mercantil. Tal visão tende a impedir análises e debates sobre seu conteúdo e suas possíveis utilizações.

Dessa maneira, a noção de serviço (ZARIFIAN, 2001a, 2001b, 2003) é compreendida como uma transformação nas condições de realização de uma atividade e nas disposições de ação de um destinatário ${ }^{1}$. Ele acrescenta que nessas transformações os “(...) efeitos são julgados positivos por este último, e são discutidos, concebidos, gerados, graças à competência dos assalariados da empresa oferecedora (e com a possível colaboração do destinatário)" (ZARIFIAN, 2003, p. 97).

Assim, para Zarifian (2006), é a transformação das "disposições de ação" dos destinatários - suas capacidades, seus recursos - que conduzirá a produção do serviço. Por outro lado, o autor acrescenta que o destinatário não deve ser compreendido como um ser passivo e meramente receptor. Trata-se, ao contrário, de um sujeito atuante, vivo, que apresenta expectativas, queixas e preferências. Isso autoriza afirmar que as disposições para ação tanto do destinatário quanto do trabalhador são povoadas por possibilidades, experimentações e expectativas que podem ou não ser atualizadas na produção do serviço, acentuando seu caráter complexo.

\footnotetext{
${ }^{1}$ Zarifian (2001a) nomeia os destinatários no setor privado como clientes, e os destinatários no setor público como usuários. Para fins de padronização, sem prejuízo nos argumentos desenvolvidos, usaremos a expressão destinatário ao longo do texto.
} 


\section{SEMINÁRIO DE PESQUISA EM CIÊNCIAS HUMANAS - SEPECH \\ Humanidades, Estado e desafios didático-científicos \\ Londrina, 27 a 29 de julho de 2016}

\section{NOVAS HABILIDADES SUBJETIVAS REQUERIDAS PELA PRODUÇÃO DO SERVIÇO}

A transformação das atividades ofertadas aos destinatários do serviço tem uma condição potencial que pode ser aumentada e diversificada, fato que agrega novas habilidades ao processo de produção do serviço em ambos os agentes - trabalhadores e destinatários. Zarifian considera ser uma vantagem falar de "disposições" nesse caso, tendo em vista que se as regras da relação são construídas socialmente, elas tendem a ser comuns e compartilháveis. Com isso, concretamente abre-se a oportunidade de discutir o processo dessas disposições, torná-las uma questão social que demanda acordos e negociações diversos entre os envolvidos.

Nesta direção, o autor enfatiza a necessidade de fazer uma análise mais situada entre as noções de produtividade e competência. Em sua concepção, a produtividade de um serviço não deve ser avaliada apenas como resultado; ela também é dependente do processo de ação e das disposições para a ação mobilizadas nos destinatários pela ação dos trabalhadores, pela ação humana.

Esta posição exige o distanciamento crítico da compreensão dos seres humanos como meros "recursos humanos" a serem explorados pelas organizações. Aceitar as prerrogativas da produção do serviço permite indicar a mobilização dos agentes envolvidos, a mobilização de seus corpos, das redes sociais, afetivas e de confiança por eles tecidas, bem como de suas disposições para agir. Mais importante ainda é que Zarifian (2006) identifica tal rede para além daqueles que prestam e produzem um serviço, reconhecendo também a mobilização de agentes múltiplos, estando eles na condição de destinatários e/ou acompanhantes do processo produção de serviço. Nesta mesma direção, Hubault afirma:

\footnotetext{
$\mathrm{Na}$ realidade, o cliente-paciente-beneficiário não é apenas um consumidor, ele está sempre inserido em uma relação que se torna, com uma intensidade bastante variável, uma coconcepção e uma coprodução. Por ela mesma, esta interpenetração das atividades desorganiza as relações prescritivas tradicionais. Solicitando a cooperação dos parceiros, ela passa a depender da implicação dos protagonistas, e mobiliza sua (inter)subjetividade como recurso produtivo (HUBAULT, 2011, p.126).
}

Deparamo-nos, portanto, com uma novidade introduzida pela "relação de serviço": ao considerar o destinatário como agente direto da produção do serviço, ganha destaque a dimensão cooperativa da produção de serviço que envolve tanto o agente trabalhador quanto o seu destinatário, numa relação cuja cooperação é o grande diferencial. Contudo, Hubault (2011, p. 130) ressalta: “(...) não existe exatamente simetria entre os protagonistas, de modo que o fator "co" não é um pré-requisito, mas um meio e um resultado".

Esta dimensão da coprodução, bem como seus efeitos nos resultados do trabalho, pode ser evidenciada no processo de trabalho da Estratégia de Saúde da Família investigada. Entre as ações prescritas à equipe de Saúde da Família está a verificação e o monitoramento da caderneta e situação vacinal direcionando à população para o início e/ou preenchimento do esquema vacinal em conformidade com os calendários de vacinação (BRASIL, 2014). Na análise do trabalho, identificou-se que garantir a 


\section{SEMINÁRIO DE PESQUISA EM CIÊNCIAS HUMANAS - SEPECH \\ Humanidades, Estado e desafios didático-científicos \\ Londrina, 27 a 29 de julho de 2016}

vacinação conforme as orientações prescritas envolve o engajamento subjetivo da enfermeira de uma das equipes de saúde da família na relação com seus destinatários do serviço.

Ao detectar a presença de certa quantidade de vacinas no freezer da Unidade de Saúde e evitar que elas perdessem a validade sem chegar aos seus destinatários, a referida enfermeira se engaja num processo de compreensão da situação. Neste processo, verifica em documentos da Unidade que algumas mães não levaram seus filhos para vacinar e a partir daí inicia um processo de busca ativa através de telefones aos responsáveis das crianças. Numa lista de sete destinatários, conseguiu contatar apenas um. Em outras situações, o responsável se comprometia em levar a criança para vacinação, mas não levava, exigindo novo contato telefônico. Em suma: garantir o adequado controle do esquema vacinal depende também dos destinatários comparecerem a Unidade para receber o referido cuidado.

Portanto, garantir esta coparticipação ativa do destinatário na produção do serviço impõe a disponibilização de meios materiais, organizacionais e cognitivos por parte dos agentes trabalhadores e da organização (HUBAULT, 2011). Esta última, além de definir a carga de trabalho e as atividades a serem realizadas, acaba tendo de enfrentar os novos problemas e dificuldades relacionais que recaem sobre a atuação de seus agentes.

Pode-se dizer, também, que no cotidiano de trabalho, a 'relação de serviço' rompe com alguns pontos de referência habituais. É impossível, por exemplo, estabelecer um enquadramento simples e prescritivo para a relação com um destinatário, visto que este último tende a resistir "àquilo que lhe é designado" a fazer (HUBAULT, 2011), abdicando de realizar sua parte de atividades na prestação de serviços. Por outro lado, constatam-se por parte das organizações, tentativas de hiper-racionalização e instrumentalização da dimensão subjetiva dos trabalhadores que, na realidade, tornamse mais um problema do que uma solução.

Assim, ao possibilitar conexões entre o universo da vida dos usuários e o universo das atividades da empresa, torna-se necessário abrir espaços de negociações e diálogos que contém com o amplo apoio e participação desses dois universos. Desde já é possível notar que estamos diante de um quadro relacional complexo, sobre o qual cabe interrogar: Como promover a abertura e a disponibilidade dos agentes trabalhadores e dos usuários para se conectar à produção de sentidos a serem atribuídos às ações prestadas e recebidas, levando em consideração o compromisso para com o bem estar de todos os envolvidos no processo? Zarifian (2006) circunscreve um ensaio de resposta evocando a construção de um espaço para o diálogo entre prestadores do serviço e seus destinatários. Tal diálogo remete à problematização do encontro entre estes dois mundos (do trabalhador e do destinatário) e conduz à seguinte interrogação: Quem são os destinatários e os "trabalhadores de serviço"? Primeiramente, cabe dizer que na produção de serviço, cada um dos participantes se conecta de maneira distinta, ocupando lugares também distintos que necessariamente remetem a experimentação de diferenças. Zarifian (2006) explica, então, que ser protagonista de uma relação social complexa como a que estamos analisando neste estudo não significa um exercício meramente funcional e prescrito, como o observado no relato do controle de vacinação.

É nesse sentido que a noção de afeto torna-se relevante para esta argumentação. Estamos o tempo todo estabelecendo relações com aquilo que nos cerca: pessoas, coisas, produções culturais, natureza e situações, para ficar em apenas alguns exemplos. 


\section{SEMINÁRIO DE PESQUISA EM CIÊNCIAS HUMANAS - SEPECH \\ Humanidades, Estado e desafios didático-científicos \\ Londrina, 27 a 29 de julho de 2016}

Em tais encontros, experimentamos as mais diversas variações de afeto que modificam nossa potência de ação. Os afetos, em uma acepção deleuziana, podem ser compreendidos como aquilo que tira o corpo do sujeito de um estado e o coloca em outro, sendo que, nesse caso, dizemos que o corpo foi afetado.

À medida que nos relacionamos na cotidianidade dos encontros, e desde que estes sejam vividos de maneira intensiva, a potência do corpo varia, podendo ir, segundo Deleuze (2002), baseado na obra de Espinosa, da alegria à tristeza. Na alegria, o corpo tem acesso a um aumento de potência, com seus desdobramos em satisfação, prazer, contentamento e plenitude. Já em situações de tristeza, essa potência diminui, decompondo o corpo e separando-o daquilo que ele pode; fato que inevitavelmente gera frustração, fadiga e desânimo. Nosso corpo abriga, portanto, a potência de afetar e de ser afetado.

Quando analisamos especificamente o trabalhador que atua na prestação de serviço, constata-se que seu cotidiano é atravessado por esses dois polos de afetação, sendo irredutível a apenas um deles. Pode-se dizer que a variação afetiva é inevitável e, ao mesmo tempo, é a condição para que o serviço seja realizado. Assim, a experiência dos encontros precipitam movimentos que impedem seus participantes a se manterem em estado fixo, uma vez que são colocadas em curso misturas, passagens e mutações afetivas que dão movimento à uma prática viva de produção de si e do outro (MANSANO, 2011). É nesse sentido que a experiência dos encontros, incluindo os laborais, pode vir a gerar a abertura para novas experimentações e aprendizagens, as quais ensejariam seus coprodutores em processos de invenção de uma existência compartilhada.

Partindo da perspectiva de que os encontros, sejam eles atravessados por alegria ou tristeza, são a condição de possibilidade para que a produção do serviço seja efetivada, isso demanda uma análise sobre o tipo de relação afetiva composta a cada nova situação de trabalho. Questionamos então: Em que medida o encontro profissional compõem ou decompõem afetivamente seus participantes (trabalhador ou destinatário)? Quais os espaços de abertura para que a prestação do serviço sirva como um potencializador de si e do outro? Múltiplas respostas podem ser dadas a essas questões desde que situadas ao contexto e a experiência vivida.

O que interessa salientar nesse tipo de análise é a chance, sempre renovada, de aprender algo com os encontros afetivos, uma vez que os mesmos são a condição para a coprodução de novas possibilidades relacionais e profissionais. Como já dito anteriormente, a base desse tipo de atividade é a coparticipação de seus agentes. Assim, estar atento aos afetos experimentados por ambos nos encontros pode ser uma fonte de aprendizagem que se renova a cada novo serviço e a cada novo desafio assumido. Daí a necessidade de romper com a linearidade simplista que coloca trabalhador e destinatário em lados contrários. Tal rompimento cria condições para avançar na problematização das implicações éticas e políticas que atravessam a prestação de serviço.

\section{DIMENSÕes ÉtiCAS E POLÍTICAS NA PRODUÇÃO DE SERVIÇO: A SAÚDE DO TRABALHADOR}

Uma segunda resposta àquela indagação sobre quem são os destinatários e trabalhadores envolvidos na produção do serviço, bem como qual sua implicação com o 


\section{SEMINÁRIO DE PESQUISA EM CIÊNCIAS HUMANAS - SEPECH \\ Humanidades, Estado e desafios didático-científicos \\ Londrina, 27 a 29 de julho de 2016}

processo, pauta-se na constatação de que tais agentes constituem-se como seres plurais. Assim, junto com o prestador do serviço comparecem no encontro laboral a organização e o destinatário, que são atravessados por valores, dúvidas, dificuldades e expectativas. Tomemos como exemplo um professor universitário que, em sua atividade cotidiana, está conectado com uma pluralidade de outros atores sociais como os secretários, chefes, colegas, técnicos e estudantes, os quais estão diretamente envolvidos na realização de sua atividade, interferido no processo laboral das mais variadas maneiras.

É nesse sentido que Zarifian conduz à compreensão da relação social como um confronto duplo: confronto entre os protagonistas e destes para com a maneira como se constitui e se estrutura a relação. Torna-se, portanto, primordial não apenas compreender os confrontos, mas acolher os desafios que nele são colocados, considerando que os protagonistas os enfrentam de formas diferentes. Os prestadores do serviço e seus destinatários apresentam uma direção e orientação diferentes, atuam sob perspectivas distintas, que podem até mesmo ser divergentes, sendo que esse exercício, com contornos éticos e políticos, acontece de maneira permanente. Portanto, identificase um confronto valioso instalado entre destinatários e prestadores do serviço em torno da maneira como o serviço é executado e recebido. Cada protagonista se apropria da relação a partir de sua própria perspectiva.

Do lado dos destinatários, a perspectiva constrói-se no registro de seu resultado: a qualidade do serviço recebido baseia-se no significado atribuído ao mesmo, suas possibilidades de apropriação e os benefícios gerados pelo serviço contratado. Já para os trabalhadores, a perspectiva em jogo se refere ao desenvolvimento de seu próprio esforço, de suas possibilidades para gerar uma transformação efetiva nos modos de existência e/ou nas disposições de ação dos destinatários.

Para que estes protagonistas (prestadores de serviços e destinatários) consigam obter um serviço bem sucedido, fica evidente a necessidade de combinar suas ações com uma dimensão ética, esta última definida pelo autor como um exercício recíproco e acessível as partícipes da relação. Assim, não estamos diante de um binômio no qual um oferece e outro recebe simplesmente o serviço. A coparticipação é a condição de possibilidade para que o serviço seja efetivado. Zarifian (2006) afirma que este desafio não é pequeno. Tanto sobre os profissionais quanto sobre os usuários recai a necessidade de desenvolver não só uma "ética de trabalho", evidenciada pela sensação de implicação com o processo, mas também o sentido da utilidade social do serviço, que torna a participação de seus agentes "socialmente úteis".

De fato, pode-se argumentar que não são todos os trabalhadores de serviço e usuários que demonstram a abertura e implicação com esse tipo de compromisso, fato que pode se reverter em uma fonte de grande divisão e frustração. Mas, é precisamente nisto que o confronto é baseado. Portanto, a produção de um serviço implica, de alguma forma, alteridade, luta, conflitos entre os dois protagonistas desta relação. Basta observar alguns episódios cotidianos de abusos verbais ou físicos aos quais "trabalhadores de serviços" podem ser submetidos pelos destinatários. O confronto necessário entre ambos pode ganhar contornos violentos, como também pode ser bem sucedido, gerando relações de cooperação.

Se o foco do serviço é a transformação dos modos de existência do destinatário (e sua família), sua construção real depende, em parte, da aposta na participação efetiva do profissional e do destinatário, tomando como base a apropriação do serviço oferecido. Um exemplo disso seria o paciente capaz de permanecer focado na sua 


\section{SEMINÁRIO DE PESQUISA EM CIÊNCIAS HUMANAS - SEPECH \\ Humanidades, Estado e desafios didático-científicos \\ Londrina, 27 a 29 de julho de 2016}

recuperação, sendo essa atitude extremamente importante para o avanço do tratamento e a possível cura. Sem seu esforço, nenhum tratamento e cuidado fará efeito. Destaca-se, portanto, a coprodução dos protagonistas na relação de serviço. Trata-se de protagonistas ativos que expressam uma potência constante de pensamento e ação conjunta. Essa cooperação acontece em meio a um complexo enfrentamento de forças que, aos poucos, dão sentido à relação bem como às maneiras de oferecer e receber o serviço.

Pautados nesta discussão, reafirma-se: o cerne da questão do serviço é uma transformação na maneira de conceber a relação entre seus participantes, uma mudança mútua. A efetividade dessa relação não pode ser reduzida ao simples desempenho de uma tarefa prescrita em uma organização ou à ocupação de uma função.

É por esta razão que Zarifian (2006) fala em "contribuição" do trabalhador de serviço, à medida que, para o serviço se concretizar, faz-se necessário considerar, em cada caso, a atividade do trabalhador e a atividade do destinatário. Recorremos ao nosso exemplo: para que o controle vacinal seja efetivo e previna o surgimento de doenças, é necessário tanto a atividade dos trabalhadores, sua mobilização frente à singularidade de seus destinatários quanto a atividade de apropriação dos destinatários das ações que lhe são oferecidas.

Do ponto de vista da atividade dos trabalhadores, é impossível tratá-la sem associá-la à sustentação de sua própria saúde. Orientadas pela perspectiva vitalista de Canguilhem (2000), a saúde é compreendida como a capacidade de criar novas normas, valores e modos de viver frente às adversidades do meio, às variações e imprevistos, ao acaso, inerentes à própria vida, ou seja, a expressão da normatividade vital dos humanos.

Neste sentido, produzir o serviço implica envolver-se e engajar-se numa relação com um destinatário, cujo modo de vida pode se inscrever na singularidade, criar meios para colaborar para apropriação das ações por parte dos destinatários exige também que os trabalhadores criem e recriem suas ações, exercendo uma experimentação vital.

Portanto, Zarifian (2005) acrescenta que a prestação de um serviço exige escuta, diálogo e cooperação, critérios que não são dados de antemão. Subjacente à cooperação há uma inerente incerteza, visto que, como já mencionado, há uma irredutível diferença de pontos de vista e interesses entre os participantes dessa relação que, por vezes, podem ser inconscientes. Nesse caso, ele chama atenção para outra forma de compreensão mútua, situada no registro do afeto. Esta forma é descrita como um entendimento tácito mútuo, sem que ocorram declarações explícitas, como, por exemplo, a empatia entre destinatário e o prestador de serviço que favorece a concretização do objetivo traçado, aumentando a potência afetiva dos envolvidos.

\section{CONSIDERAÇÕES FINAIS}

O posicionamento defendido por Zarifian permite-nos enfatizar que a produção de serviço extrapola o simples momento de face a face, quando da compra ou acesso ao benefício ofertado. O serviço é gerado numa relação social complexa, sobre a qual é necessário continuar explorando seus desdobramentos sociais e afetivos.

A ênfase atribuída à apropriação da atividade, potencial e real do destinatário, conduz ao seguinte questionamento: Como o serviço pode transformar as condições de 


\section{SEMINÁRIO DE PESQUISA EM CIÊNCIAS HUMANAS - SEPECH \\ Humanidades, Estado e desafios didático-científicos \\ Londrina, 27 a 29 de julho de 2016}

atividade dos destinatários? Entende Zarifian (2005) que a efetividade de um serviço está atrelada a algum esforço pelo mesmo que é irredutível a atividade do trabalhador. Como discutido anteriormente, o destinatário também participa do processo ao se apropriar da oportunidade oferecida pelo serviço, pode recuperar a saúde, agregar conhecimento, ter acesso a prazeres de diferentes tipos, enfim, uma lista ampla de sensações e afetos. Porém, isso exige um esforço tanto do trabalhador quanto do destinatário para que o serviço se torne eficaz.

Pode-se concluir, portanto, que a dimensão de coprodução levanta uma dupla problematização: tanto os prestadores quanto os destinatários estão diretamente implicados com a criação do serviço, podendo avaliar seus limites, possibilidades transformadoras e benefícios. Assim, diante da relação experimentada no serviço, o resultado é condizente com o esperado por seus protagonistas? Atendeu as expectativas de ambos e colaborou para transformar suas condições iniciais de existência? Responder a estas questões de maneira conjunta não é uma tarefa simples uma vez que, culturalmente, ainda é muito naturalizada a ideia de que o usuário "tem sempre razão". Seguir na direção de desnaturalização desse pressuposto é, portanto, primordial para que a produção do serviço se reconfigure. Isso exige uma mudança de perspectiva: a execução de um serviço é dinâmica, incontrolável e implica, necessariamente, a cooperação entre os agentes envolvidos.

\section{REFERÊNCIAS}

BRASIL. Secretaria de Vigilância em Saúde. Departamento de Vigilância das Doenças Transmissíveis. Manual de Normas e Procedimentos para Vacinação / Ministério da Saúde, Secretaria de Vigilância em Saúde, Departamento de Vigilância das Doenças Transmissíveis. - Brasília: Ministério da Saúde, 2014.

CANGUILHEM, G. O normal e o patológico. 5. ed. Rio de Janeiro: Forense Universitária, 2000.

DELEUZE, G. Espinosa: Filosofia prática. São Paulo: Escuta, 2002.

HUBAULT, F. Os desafios relacionados à mobilização da subjetividade na relação de serviço. In: SZNELWAR, L. I. (Org.). Saúde dos bancários. São Paulo: Publisher Brasil : Editora Gráfica Atitude Ltda, 2011, p.125-149.

MANSANO, S. R. V. Clínica e potência: algumas considerações sobre a experiência dos encontros em Gilles Deleuze. Mnemosine, 7(2), p. 64-74, 201.

ZARIFIAN, P. Objetivo competência. Por uma nova lógica. São Paulo: Atlas, 2001a.

- Mutações dos sistemas produtivos e competências profissionais: a produção industrial do serviço. In: SALERNO, M. S. (Org.) Relação de Serviço: produção e avaliação. São Paulo: Editora Senac, 2001b, p. 67-94. 


\section{SEMINÁRIO DE PESQUISA EM CIÊNCIAS HUMANAS - SEPECH \\ Humanidades, Estado e desafios didático-científicos \\ Londrina, 27 a 29 de julho de 2016}

O modelo da competência: trajetória, história, desafios atuais e propostas. São Paulo: Editora Senac São Paulo, 2003.

Rapport Social de Service et Capitalisme: quelques hypotheses. Intervention de Philippe Zarifian lors du séminaire du laboratoire Genre, Travail et Mobilité (10 janvier 2005). Disponível em < http://philippe.zarifian.pagesperso-orange.fr/page123.htm $>$. Acesso em: Out. 2011.

Histoire et enjeux du service durable. Intervention réalisée le 15 juin 2006 dans le cadre du colloque de Cerisy, intitulé: "L'économie des services pour un développement durable"). Disponível em: http://philippe.zarifian.pagesperso-orange.fr/page152.htm Acesso em: Ago. 2011.

Le travail comme prise d'initiative. Paris, le 31 août 2007 Disponível em: http://philippe.zarifian.pagesperso-orange.fr/page175.htm Acesso em: Ago. 2011 